\title{
Presidential address to the 41st Annual Congress of European Hernia Society. Evidence, innovation and education in hernia repair, 11-14 September 2019 in Hamburg
}

\author{
Wolfgang Reinpold ${ }^{1}$ (D)
}

Received: 13 August 2019 / Accepted: 18 August 2019

(c) Springer-Verlag France SAS, part of Springer Nature 2019

Dear colleagues, dear hernia friends,

The 41st Annual Congress of the European Hernia Society will be held from 11th to 14th September 2019 in Hamburg. On this occasion we will also celebrate EHS'sformerly GREPA, 40th anniversary! GREPA, founded by a group of French surgeons with a special interest in hernia repair, was the world's first hernia society. At the opening ceremony and during the congress, we want to honor and celebrate the pioneers of herniology and their vision.

Today, the European Hernia Society can be considered the cradle of modern herniology.

Over the last four decades, hernia and abdominal wall repair have developed into one of the most fascinating and innovative specialties in surgery and many countries have established hernia societies and associations of abdominal wall repair. The abdominal wall surgeon specialization, certified and endorsed by the „Union Européenne des Médecins Spécialistes" is on the horizon and will likely be established soon.

We can be pround of major improvements in hernia repair which were made possible mainly by the advent of mesh and laparoendoscopy. Only with the support and collaboration with our industry partners these important advances were possible.

Despite all this progress in our treatment options, hernias and abdominal wall defects remain a global scourge with very diverse and often complex manifestations. Many questions remain to be answered and after all achievements of the past we are now entering a new age. As in other fields of modern life digitalisation, virtual reality and robotics will

Wolfgang Reinpold

wreinpold@gmx.net

1 Gross-Sand Hospital Hamburg, Academic Teaching Hospital of Hamburg University Hospital, Gross-Sand 3, 21107 Hamburg, Germany play an ever more important role and will help us to improve abdominal wall repair.

The motto of the 41st EHS Congress is "Evidence, Innovation and Education in Hernia Repair".

In fact, a vast amount of new evidence, innovations and new ways of education will be presented at the EHS2019HAMBURG Congress. We have received an impressive amount and quality of excellent abstracts from all over the world.

Many high-quality trials, new guidelines and classifications will be presented at EHS2019 Hamburg Congress for the first time. Numerous controversial topics will be presented and discussed in interactive crossfire debates. Interactive sessions will allow you to participate with live interaction. The opinion of each delegate matters!

Of course all hot topics like the new minimal invasive techniques of abdominal wall repair, management of complex hernias, new materials, news from the registries, certification of hernia centers, impact of new medical device regulation and more will be addressed.

With education being one of the main topics, we want to give a platform especially to young surgeons from all over the world to learn and present. For this purpose several young-surgeons- and speed-lecture-sessions have been arranged.

Featuring virtual reality and conventional simulation models, an Education Lab will give an overview on the new ways and options of teaching and training.

We are very honored that you will hopefully meet a large international faculty at the EHS2019HAMBURG Congress. For further improvement of hernia treatment let us all share our knowledge and celebrate international hernia days in a friendly and open-minded atmosphere.

Please join us because your participation matters for the sake of our patients. 
Warm regards from Hamburg und herzliche Grüsse.<smiles>C=CCCC</smiles>

Wolf́gang Reinpold

Congress President

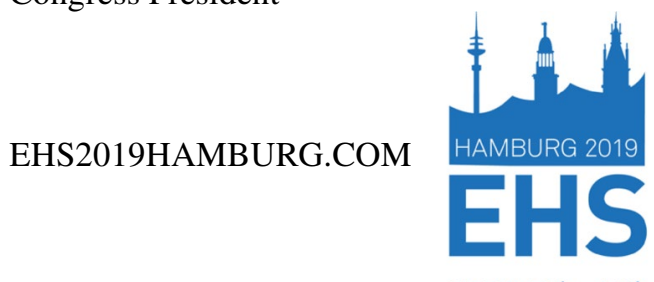

SEPT $11^{\text {th }}-14^{\text {th }}$
Publisher's Note Springer Nature remains neutral with regard to jurisdictional claims in published maps and institutional affiliations. 